\title{
RELATIONSHIP ANALYSIS OF WALL TRANSMITTANCE AND WIND SPEED WITH NUMERICAL METHOD
}

\section{F. SZODRAI}

Department of Building Services and Building Engineering, Faculty of Engineering, University of Debrecen, H-4028 Debrecen, Ótemető u. 2-4, Hungary

E-mail: szodrai@eng.unideb.hu

In heat transfer calculations, transmittance values are often used as a constant in practice. With the spread of dynamic simulations, it opens an opportunity to study the sensitivity of the external effects (e.g., wind speed) on buildings. With the proper amount of result, adequate simplifications can be made to reduce the duration of the simulations. In this paper several steady sate simulations were carried out by Ansys 19.1. Academic version. In the examined cases three building structures were examined with different thermal resistances. Average initial air temperature difference was applied on the two sides of the structures, at the cold side the wind speed was varied, while at the warm side natural convection was present. The surface temperatures and the heat flux were monitored and the transmittances were calculated as a result.

Keywords: CFD, numerical, heat transfer, transmittance, wind

\section{Nomenclature}

$c \quad-$ specific heat $\left[\mathrm{J} \mathrm{kg}^{-1} \mathrm{~K}^{-1}\right]$

$C_{f}-$ skin friction coefficient $[-]$

$d$ - distance, thickness [m]

$h-$ thermal transmittance $\left[\mathrm{W} \mathrm{m}^{-2} \mathrm{~K}^{-1}\right]$

$R$ - thermal resistance $\left[\mathrm{m}^{2} \mathrm{~K} \mathrm{~W}^{-1}\right]$

$\mathrm{Re}$ - Reynolds number [-]

$T-$ temperature $[\mathrm{K}]$

$u$ - flow velocity or wind speed $\left[\mathrm{m} \mathrm{s}^{-1}\right]$

$U-$ heat transfer coefficient $\left[\mathrm{W} \mathrm{m}^{-2} \mathrm{~K}^{-1}\right]$

\section{Introduction}

For heat transfer calculations engineers usually have two methods simplified and dynamic. In simplified or standardized methods, we can get a rough estimate that can be widely accepted. The dynamic simulations offer a precise solution, where measured parameters serve as input parameters and depending on the amount of these parameters we can decide how accurate should the results be. Depending on the simplicity of the model it can be 1, 2 or 3 dimensional. For 2 - and

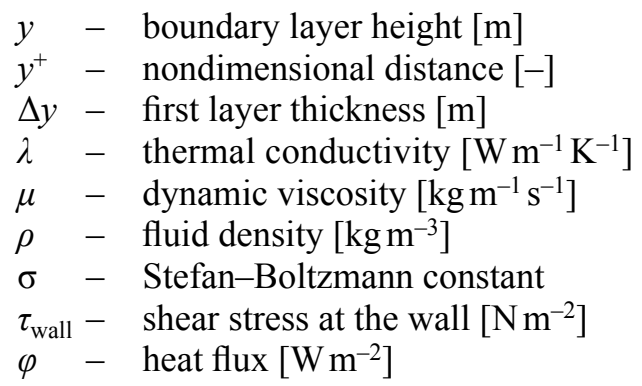

3-dimensional calculations finite volume method can be used which is a field of the computational fluid dynamics (CFD). These calculations can be steady state simulations or transient simulations. The steady state simulations can show us a state when the building is in thermal equilibrium while the transient cases how it can change during a period. The transient cases and large geometries require huge computational power. It provides knowledge as to what measured parameters should be taken in account (what simplifications can be made) to reduce the amount of calculation [1-3].

Open Acces statement. This is an open-access article distributed under the terms of the Creative Commons Attribution 4.0 International License (https://creativecommons.org/licenses/by/4.0/), which permits unrestricted use, distribution, and reproduction in any medium, provided the original author and source are credited, a link to the CC License is provided, and changes - if any - are indicated. (SID_1) 


\subsection{Heat transfer}

The heat transfer coefficient $(U)$ or its inverse, the thermal resistance value $(R)$ is used when a building is evaluated from a building energetic point of view. For example, in Hungary for wall structures the total thermal resistance has to be at least $R_{\text {total }}=4.17 \mathrm{~m}^{2} \mathrm{~K} \mathrm{~W}^{-1}$ to achieve the nearly zero energy demand building requirement. This value includes the thermal resistance of the surface which is $4 \%$ of the total value, according to the Decree on the Determination of the Energy Characteristics of Buildings [4].

The total thermal resistance is the summary of the internal $\left(R_{i}\right)$ and the external $\left(R_{e}\right)$ surface and the wall structure's $\left(R_{\text {wall }}\right)$ thermal resistance as Eq. (1) shows:

$$
R_{\text {total }}=R_{i}+R_{\text {wall }}+R_{e} .
$$

The internal and the external surface resistances are depending on the heat flux $(\varphi)$ through the wall, the wall surface temperature $\left(T_{\text {surface }}\right)$ and the air temperature $\left(T_{\text {air }}\right)$. This connection and the calculation of the thermal transmittance ( $h$ can be seen in Eq. (2).

According to the MSZ EN ISO 6946:2017 [5] standard the thermal transmittance $(h)$ has a convective and a radiation component.

$$
R_{\text {surface }}=\frac{T_{\text {surface }}-T_{\text {air }}}{\varphi}=\frac{1}{h}=\frac{1}{h_{c}+h_{r}} .
$$

The convective component $\left(h_{c}\right)$ depending on wind speed $(u)$ near the building surface:

$$
h_{c}=4+4 u \text {. }
$$

The radiative component $\left(h_{r}\right)$ is depending on the emissivity factor (usually it is 0.9 ) and on the mean temperature $\left(T_{m}\right)$ in $[\mathrm{K}]$ :

$$
h_{r}=\varepsilon 4 \sigma T_{\mathrm{m}}^{3},
$$

where the Stefan-Boltzmann constant is $\sigma=5.67$ $\times 10^{-8} \mathrm{~W} \mathrm{~m}^{-2} \mathrm{~K}^{-4}$.

In standardized cases the thermal transmittance is constant (MSZ EN ISO 6946:2017) and it is given depending by the orientation of the structure [5].

\subsection{Turbulence and near-wall modelling}

Turbulence models are used to simplify the turbulent fluctuations of the flow. Various models have been developed that can be used to approximate turbulence based on the Reynolds Averaged Navier-Stokes equations. In the examined case a near-wall model will be made, to express how the heat transfer of the wall will respond to the air flow. Turbulence models and mesh- ing have a big impact on the convergence at near-wall flows. The purpose of the near-wall model is to describe the viscous effects at the wall and the rapid variation of flow variables that occur within the boundary layer region. The two approaches that can be chosen are the wall function and the Low-Reynold-Number. The wall function is a simplified empirical approach and it requires less computational source and lower mesh density, in these modes the $k-\varepsilon$ or large eddy turbulence model can also be used. The Shear Stress Transport (SST) or $k-\omega$ models are suitable for lowRe method. The approach requires a fine mesh in the near-wall zone and correspondingly large number of nodes. For the mesh independency calculation, the non-dimensional thickness $y^{+}$value is needed, if this value is lower than 1 in near wall cases and if higher than 11 then wall function approach is used [6-10].

The estimation of the first layer thickness is the following [11]:

$$
\begin{gathered}
R_{e}=(\rho u y) / \mu, \\
C_{f}=0.026 R_{e}^{-1 / 7}, \\
\tau_{\text {wall }}=C_{f} \rho u^{2} / 2, \\
u_{\text {fric }}=\left[\tau_{\text {wall }} / \rho\right]^{1 / 2}, \\
\Delta y=\left[\left(y^{+} \mu\right) /\left(u_{\text {fric }} \rho\right)\right] .
\end{gathered}
$$

From Eqs (5)-(9), first the desired $y^{+}$needed to be given with the parameters (dynamic viscosity $(\mu)$, density $(\rho)$, velocity $(u)$, boundary layer height $(y))$ of the fluid. To achieve the boundary layer height $(y)$ and the thickness of the first layer $(\Delta y)$ several iterations are needed.

\section{Materials and methods}

\subsection{Simulation model}

The simulations were carried out with Ansys 19.1. Academic version, where transmittances of different wall structures were examined. Average initial air temperatures (cold and warm side), layer thicknesses, specific heat and thermal conductivities were given as boundary conditions to attain heat fluxes and (cold and warm side) surface temperatures. It was important to highlight that the temperature was given as initialized temperature, because after a few iterations, the air domain temperature will change. After the convergence the undisturbed flow will still have the initial temperature. A simulation model validation was made first in Ansys CFX 19.1, where the input and output data were provided from a previous measurement [12]. In these models, different turbulences were applied. Full buoy- 
ancy model was used, in previous laboratory measurements [12] it was concluded that the direction of wind was slightly affecting the transmittance although the existence of the buoyancy influences the transmittance at vertical walls. Some sampling simulations were made to strengthen this fact, although these were not presented in this paper. In the examined cases the direction of the wind and the gravity was the same. With these restrictions a 2-dimensional 1 mesh wide and $1 \mathrm{~m}$ metre long geometry was made, that was built from $0.0015 \mathrm{~m}$ tall hexahedrons. For heat radiation modelling surface to surface discrete transfer model was used, without direct radiation [13].

\subsection{Boundaries}

Four different geometries were created where every geometry had a wall structure with a cold and a warm side. The structure base was a $0.25 \mathrm{~m}$ thick brick $\left(\lambda_{\text {brick }}=0.72 \mathrm{~W} \mathrm{~m}^{-1} \mathrm{~K}^{-1} ; c_{\text {brick }}=835 \mathrm{~J} \mathrm{~kg}^{-1} \mathrm{~K}^{-1}\right)$, on the cold side of the brick wall a (structure 2) $0.135 \mathrm{~m}$ and $0.2 \mathrm{~m}$ (structure 3 ) thick expanded polystyrene insulation ( $\lambda_{\text {insulation }}=0.039 \mathrm{~W} \mathrm{~m}^{-1} \mathrm{~K}^{-1}$; $c_{\text {insulation }}=1460 \mathrm{~J} \mathrm{~kg}^{-1} \mathrm{~K}^{-1}$ ) was applied, in one case it was uninsulated (structure 1). Both sides of the wall structure were mortared with $0.015 \mathrm{~m}$ thick plaster $\left(\lambda_{\text {plaster }}=0.8 \mathrm{~W} \mathrm{~m}^{-1} \mathrm{~K}^{-1} ; c_{\text {plaster }}=920 \mathrm{~J} \mathrm{~kg}^{-1} \mathrm{~K}^{-1}\right)$. With these combinations three wall structures with $R_{1}=$ $0.6 \mathrm{~m}^{2} \mathrm{KW}^{-1} ; R_{2}=4 \mathrm{~m}^{2} \mathrm{~K} \mathrm{~W}^{-1} ; R_{3}=5.7 \mathrm{~m}^{2} \mathrm{KW}^{-1}$ thermal resistance $\left(R_{\text {wall }}\right)$ (without the surface resistance) were attained. For the transmittance analysis $0.3 \mathrm{~m}$ thick ideal air domain were set on the plasters.

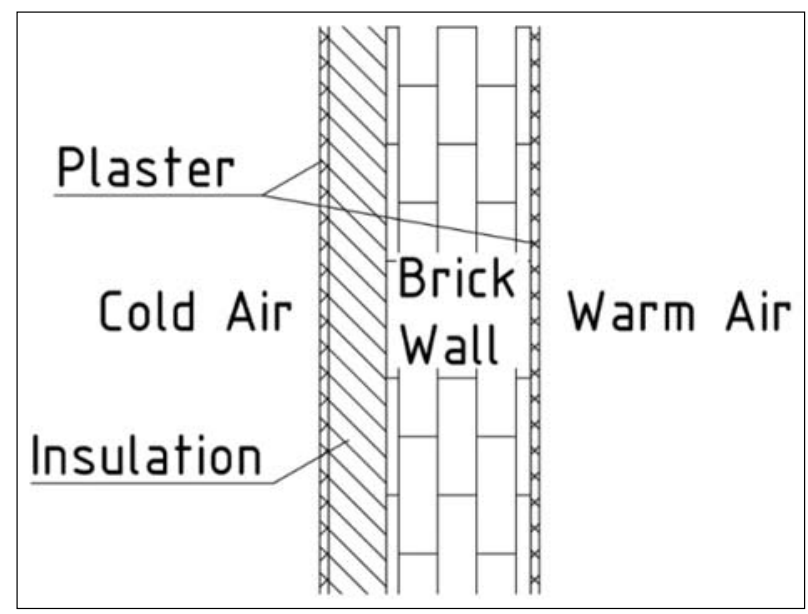

Fig. 1. Scheme of the simulated wall structure

In practice the plastered surfaces are coarse, also manufacturers usually do not provide the surface roughness, only the diameters of the plaster particles. The surface roughness in practice could change the velocity distribution coefficient [14]. Surfaces with high roughness can decrease the velocities near the wall when the turbulence is high. The MSZ EN ISO 6946:2017 [5] standard does not define the velocity distribution near the wall. Knowing this fact and for simplicity's sake no-slip surfaces were set without surface roughness. The cold side wind speed near the wall was set with pre-made wall functions where the average free stream velocity was $1 \mathrm{~m} \mathrm{~s}^{-1} ; 2 \mathrm{~m} \mathrm{~s}^{-1} ; 3 \mathrm{~m} \mathrm{~s}^{-1}$; $4 \mathrm{~ms}^{-1} ; 5 \mathrm{~m} \mathrm{~s}^{-1} ; 7 \mathrm{~m} \mathrm{~s}^{-1} ; 10 \mathrm{~m} \mathrm{~s}^{-1}$. Surface resistances were also calculated for these wind speeds in MSZ EN 6946 [5]. At the warm side natural convection was present. The initial average cold side temperature was set to $253.15 \mathrm{~K}$ while the initial average warm side temperature was $293.15 \mathrm{~K}$. These temperatures were close to the validation temperatures, that is why it was chosen, the MSZ EN ISO 6946:2017 calculates for $263.15 \mathrm{~K}$ cold side temperature. The cold side temperature sensitivity dependenci was not in the scope of this paper $[15,16]$.

\section{Results and discussion}

\subsection{Validation}

For the validation of the model it is essential to achieve two requirements. In the first 500 iterations the residuals of the solution convergence must be at least under $10^{-4}$ while $10^{-5}$ considered to be well converged. The calculated and the previously measured heat flux [12] deviation needed to be minimized. For the validation the following input parameters were used: $T_{\text {cold }}=$ $256.815 \mathrm{~K} ; T_{\text {warm }}=297.972 \mathrm{~K} ; u=1 \mathrm{~m} \mathrm{~s}^{-1}$. The monitored values converged to $10^{-5}$ during the simulations. In Table 1 it can be seen that the calculated errors for the surface temperatures were $0-1 \%$ and for the heat fluxes they were $13-23 \%$.

Table 1. Turbulence model errors

\begin{tabular}{lcccc}
\hline \multirow{2}{*}{ Case } & \multirow{2}{*}{ Unit } & \multicolumn{2}{c}{ Surface temperature } & Heat flux \\
\cline { 3 - 5 } & & Warm & Cold & {$\left[\mathrm{W} \mathrm{m}^{-2}\right]$} \\
\hline Validation data & {$[\mathrm{K}]$} & 291.71 & 261.02 & 58.28 \\
laminar & {$[\mathrm{K}]$} & 292.36 & 266.57 & 66.74 \\
Error & {$[\%]$} & 0 & -2 & -13 \\
$k-\omega$ & {$[\mathrm{K}]$} & 294.61 & 262.19 & 75.89 \\
Error & {$[\%]$} & -1 & 0 & -23 \\
SST & {$[\mathrm{K}]$} & 294.18 & 262.48 & 74.46 \\
Error & {$[\%]$} & -1 & -1 & -22 \\
\hline
\end{tabular}

Although the error values were the lowest at the laminar flows in the validation case, at higher velocities the laminar flow cannot produced adequate even velocity distribution. In the SST model the inlet velocities were given in wall functions (first $0.05 \mathrm{~m}$ presented in Fig. 2). From Fig. 3 it can be observed that 


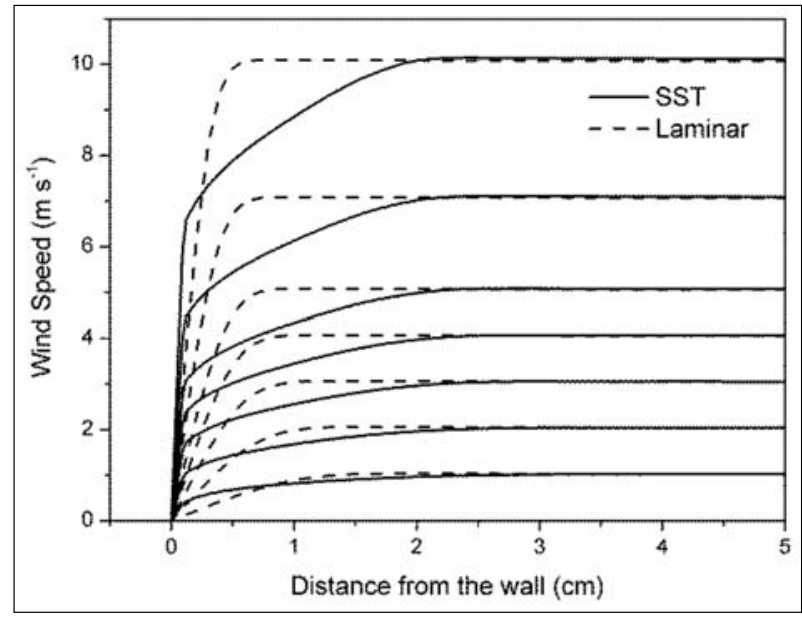

Fig. 2. SST and laminar wall functions

$0.03 \mathrm{~m}$ away from the smooth vertical wall surface, the velocity of the wind becomes undisturbed by the wall surface.

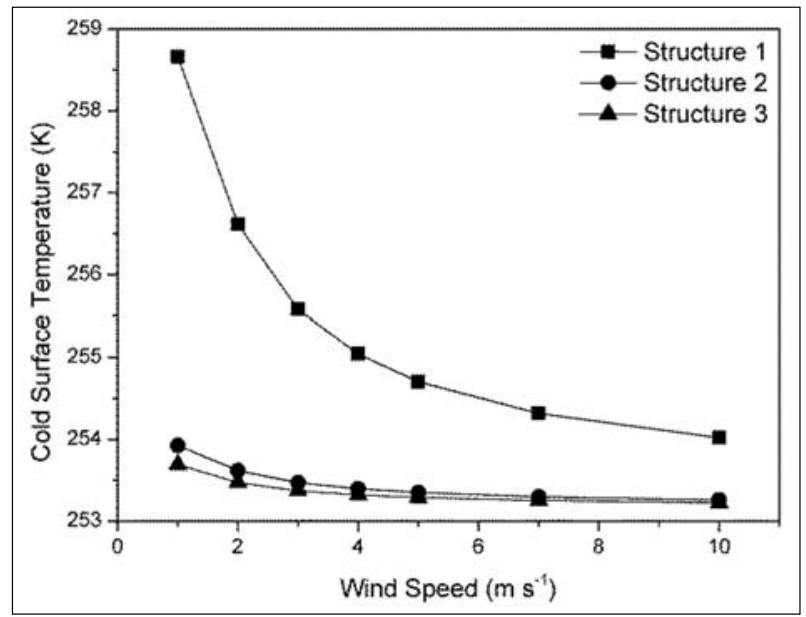

Fig. 4. Relation of cold surface temperature-wind speed

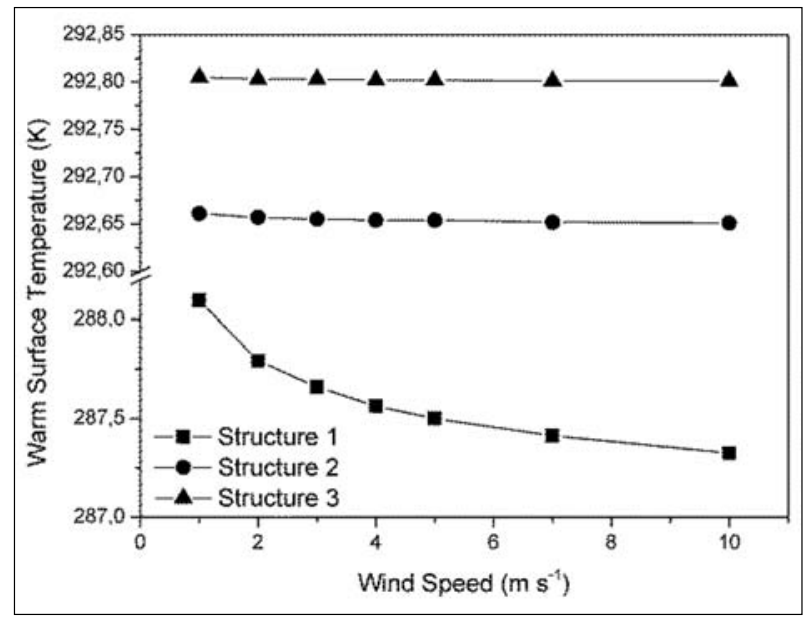

Fig. 5. Relation of warm surface temperature-wind speed

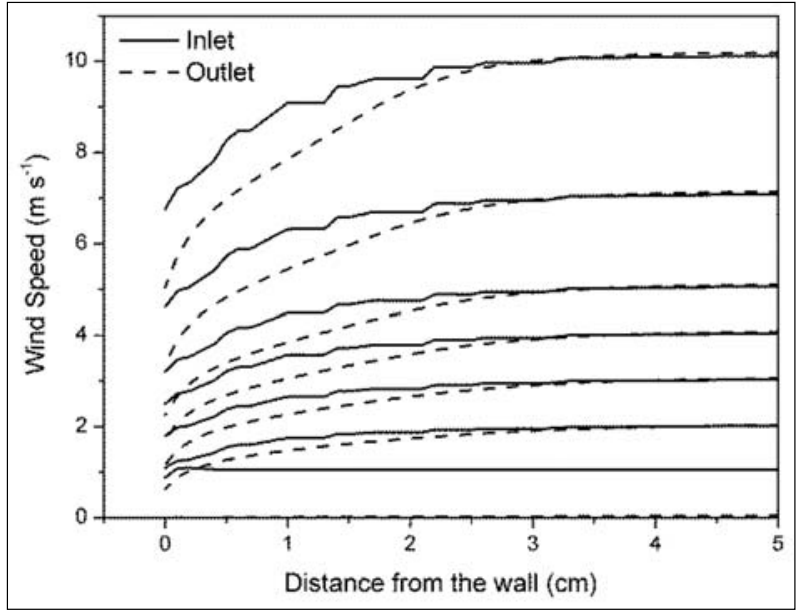

Fig. 3. Inlet and outlet velocity distribution in SST model

Difference between the inlet and outlet velocities was minimal in the SST model (see Fig. 3), while in the laminar model, due to the viscous effect the velocities decreased to $0 \mathrm{~m} \mathrm{~s}^{-1}$. These assumptions served as purpose to use the SST model.

\subsection{Results from SST model}

The results from the SST models can be seen in Figs 4-8. The calculated values were presented in function of the average free flow velocities. From the results of the calculations, it can be concluded that with higher thermal resistance the structures were less sensitive to the external effects. For example, structures 2 and 3 with a $R_{2}=4 \mathrm{~m}^{2} \mathrm{KW}^{-1}$ and $R_{3}=\mathrm{m}^{2} \mathrm{KW}^{-1}$ thermal resistance, the changes in the surface temperatures and heat flux were minimal. Attributable to the insulation, it keeps the cold side surface temperature at low, while the warm side surface temperature is kept at high level. The wind speed has a strong inverse relationship to the thermal properties of structure 1 .

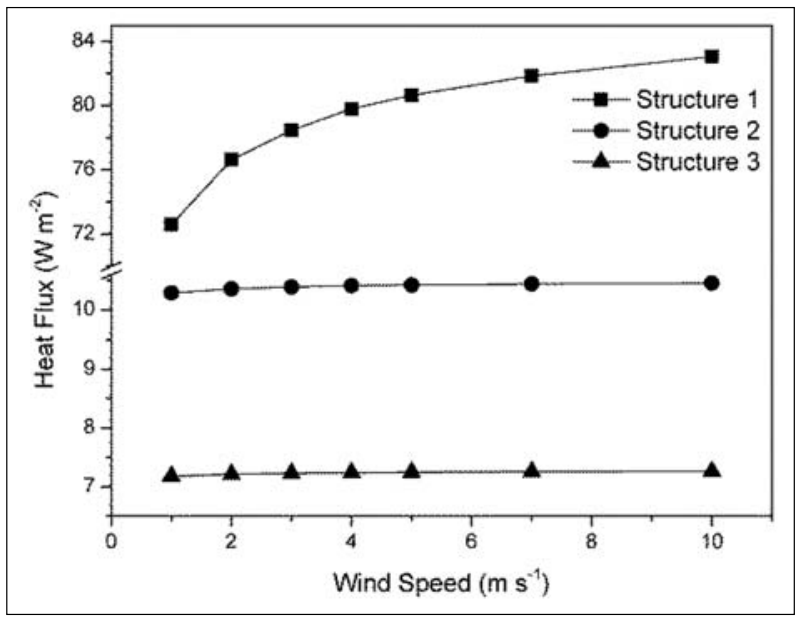

Fig. 6. Relation of heat flux-wind speed 


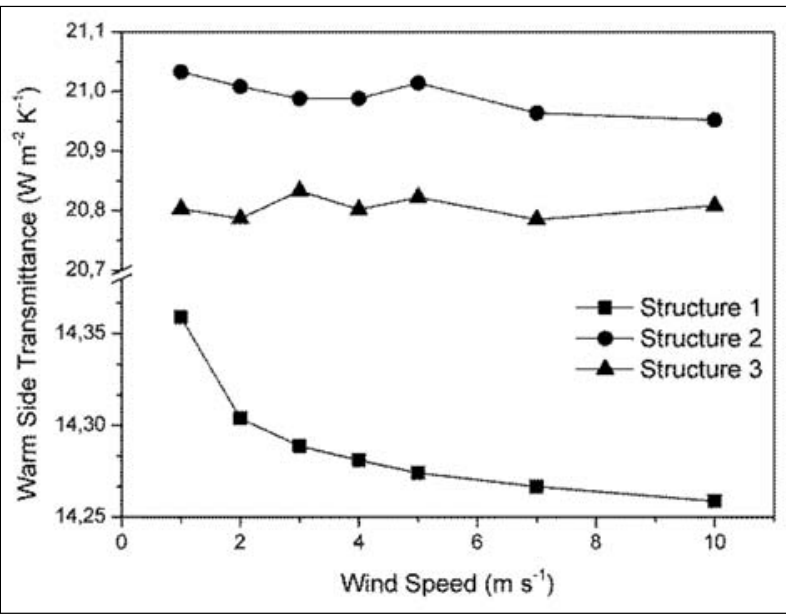

Fig. 7. Relation of warm side transmittance-wind speed

\subsection{Transmittance changes}

The transmittance was calculated with Eq. (2), using the parameters from the results (Figs 5-7) and the initial average air temperatures. The warm side transmittance follows the trend of thermal properties that can be seen in Fig. 6. While the cold side transmittance is clearly linearly dependent from the wind speed. Ozgen et al. showed that, at lower temperature, the value of the radiative component of the transmittance is decreasing [1]. The examined relationship differs from the MSZ EN ISO 6946 [5], the standard assumes twice larger thermal resistance at wind speeds above $3 \mathrm{~m} \mathrm{~s}^{-1}$. For the 1 and $2 \mathrm{~m} \mathrm{~s}^{-1}$ cases the difference is small. Rhetorical question can be asked. At what velocities should we calculate? What is the most frequent wind speed in urban area or along the buildings and how frequent it is in the heating or in the cooling season? The results show that in the practical design the wind speed is less than $1 \mathrm{~m} \mathrm{~s}^{-1}$.

\section{Conclusion}

In this paper, 21 independent 2D thermal simulation models were carried out with Ansys 19.1. Academic version. It was shown that for near-wall CFD model validation, the measurement of the free stream velocity has to be at least $0.005 \mathrm{~m}$ away from the vertical aligned wall. For low turbulence near-wall modelling it was concluded that the SST mode is preferable, although it showed significant error in the heat flux. Laminar turbulence model had to be disregarded, because the viscous effects could not guarantee the even velocity distribution along the fluid domain.

It was also shown that the cold side transmittance is only influenced by the free stream velocity and the structures' thermal properties did not have an effect on it. It has to be mentioned that the total thermal surface resistance in the simulation cases were var-

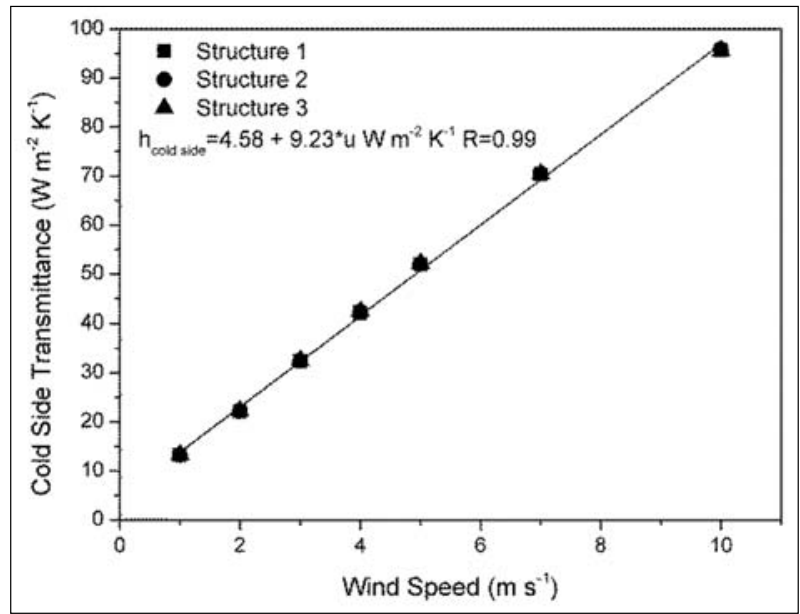

Fig. 8. Relation of cold side transmittance-wind speed

ied between $0.146-0.058 \mathrm{~m}^{2} \mathrm{KW}^{-1}$ while in practice in Hungary $0.17 \mathrm{~m}^{2} \mathrm{KW}^{-1}$ is used. From the results it can be also concluded that in Hungary the thermal surface resistance is calculated when the wind speed is less than $1 \mathrm{~m} \mathrm{~s}^{-1}$ near the building. On surfaces where high wind speeds often occur there should be thicker insulation layers due to the decreased total thermal resistance.

Compared to a real-life steady state measurement, the steady state thermal CFD simulation requires a fraction of the research time. Moreover, it lets the researcher examine more and more cases. With the vast amount of results and conclusions the heat transfer calculations can be simplified, although the measurements are extremely important to validate the simulation values.

\section{Acknowledgements}

The publication is supported by the EFOP-3.6.1-162016-00022 project. The project is co-financed by the European Union and the European Social Fund

\section{References}

[1] Acikgoz O., Kincay O. (2015), Experimental and numerical investigation of the correlation between radiative and convective heat-transfer coefficients at the cooled wall of a real-sized room. Energy and Buildings, 108(1), 257-266.

[2] Seddiq M., Maerefat M., Mirzaei M. (2014), Modeling of heat transfer at the fluidesolid interface by lattice Boltzmann method. International Journal of Thermal Sciences, $75,28-35$.

[3] Lakatos Á., Csáky I., Kalmár F. (2015), Thermal conductivity measurements with different methods: a procedure for the estimation of the retardation time. Materials and Structures, 48(5), 1343-1353.

[4] 7/2006. (V. 24.) TNM Decree on the Determination of the Energy Characteristics of Buildings, 2006. 
[5] MSZ EN ISO 6946:2017, Building components and building elements. Thermal resistance and thermal transmittance. Calculation method (ISO 6946:2017), 2017.

[6] Cengel A. Y., John M. C. (2006), Fluid Mechanics. New York: McGraw-Hill ISBN 0-07-247236-7.

[7] Wilcox D. C. (2000, Turbulence Modelling for CFD, La Canada: DCW Industries CA 91011, p. 314.

[8] Menter F. R. (1994), Two-equation eddy-viscosity turbulence models for engineering applications. AIAA-Journal, 32(8), 1598-1605.

[9] Patel V. C., Rodi W., Scheuerer G. (1985), Turbulence models for near-wall and low Reynolds number flows - A review. AIAA Journal, 23(9), 1308-1319.

[10] Manz H. (2003), Numerical simulation of heat transfer by natural convection in cavities of facade elements. Energy and Buildings, 35(3), 305-311.

[11] White F. M. (2011), Fluid Mechanics. 7th edition, New York: McGraw-Hill ISBN 978-0-07-352934-9.
[12] Szodrai F., Lakatos Á. (2017), Effect of the air motion on the heat transport behaviour of wall structures. International Review of Applied Sciences and Engineering, 8(1), 67-73.

[13] Wacławczyk M., Pozorski J. (2003), Modelling of turbulent flow in the near-wall region using PDF method. Journal of Theoretical and Applied Mechanics, 41(1), 3-18.

[14] Cernik P. (1990), Influence of wall roughness on wind pressure distribution and ventilation losses in Netherlands. In: International CIB W67 Symposium "Energy, Moisture and Climate in Buildings", Rotterdam.

[15] Bottema M. (1996), Roughness parameters over regular rough surfaces: Experimental requirements and model validation. Journal of Wind Engineering and Industrial Aerodynamics, 64, 249-265.

[16] Lopes M. (2013), Numerical calculation of the wind action on buildings using Eurocode 1 atmospheric boundary layer velocity profiles. Wind and Structures, 6, 487. 